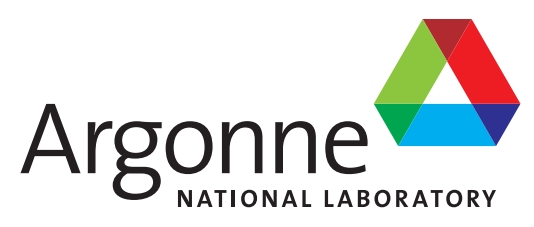

ANL-12/25

\title{
Vehicle Technologies Program Government Performance and Results Act (GPRA) Report for Fiscal Year 2012
}

Energy Systems Division 


\begin{abstract}
About Argonne National Laboratory
Argonne is a U.S. Department of Energy laboratory managed by UChicago Argonne, LLC under contract DE-AC02-06CH11357. The Laboratory's main facility is outside Chicago, at 9700 South Cass Avenue, Argonne, Illinois 60439. For information about Argonne and its pioneering science and technology programs, see www.anl.gov.
\end{abstract}

\title{
Availability of This Report
}

This report is available, at no cost, at http://www.osti.gov/bridge. It is also available on paper to the U.S. Department of Energy and its contractors, for a processing fee, from:

U.S. Department of Energy

Office of Scientific and Technical Information

P.O. Box 62

Oak Ridge, TN 37831-0062

phone (865) 576-8401

fax (865) 576-5728

reports@adonis.osti.gov

\begin{abstract}
Disclaimer
This report was prepared as an account of work sponsored by an agency of the United States Government. Neither the United States Government nor any agency thereof, nor UChicago Argonne, LLC, nor any of their employees or officers, makes any warranty, express or implied, or assumes any legal liability or responsibility for the accuracy, completeness, or usefulness of any information, apparatus, product, or process disclosed, or represents that its use would not infringe privately owned rights. Reference herein to any specific commercial product, process, or service by trade name, trademark, manufacturer, or otherwise, does not necessarily constitute or imply its endorsement, recommendation, or favoring by the United States Government or any agency thereof. The views and opinions of document authors expressed herein do not necessarily state or reflect those of the United States Government or any agency thereof, Argonne National Laboratory, or UChicago Argonne, LLC.
\end{abstract}




\section{Vehicle Technologies Program Government Performance and Results Act (GPRA) Report for Fiscal Year 2012}

prepared by

J. Ward ${ }^{1}$, T.S. Stephens ${ }^{2}$, and A.K. Birky ${ }^{3}$

1 U.S. Department of Energy, Office of Energy Efficiency and Renewable Energy

${ }^{2}$ Argonne National Laboratory, Center for Transportation Research

${ }^{3}$ TA Engineering, Baltimore, Maryland

March 2012

Work sponsored by U.S. Department of Energy,

Office of Energy Efficiency and Renewable Energy,

Vehicle Technologies Program 



\section{CONTENTS}

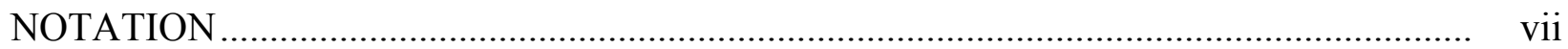

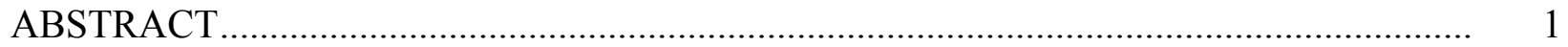

1 INTRODUCTION AND PROGRAM OVERVIEW ............................................................ 2

2 ASSUMED BUDGET PROJECTIONS ………….......................................................

3 PROGRAM ACTIVITIES, MILESTONES, AND OUTPUTS …………………….......... 4

3.1 Batteries and Electric Drive Technology ………....................................................... 4

3.2 Advanced Combustion Engine R\&D .................................................................... 5

3.3 Materials Technology R\&D .............................................................................. 8

3.4 Fuels and Lubricant Technologies R\&D............................................................ $\quad 10$

3.5 Vehicle and Systems Simulation and Testing ......................................................... 13

3.6 Outreach, Deployment, and Analysis.................................................................... 14

4 TRANSLATING PROGRAM GOALS INTO ENERGY MODEL

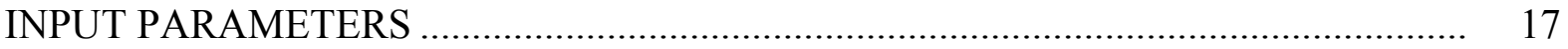

4.1 Baseline "No Program" Case ............................................................................... 17

4.2 GPRA Advanced Technology Modeling …………............................................... 18

5 RESULTS OF MODELING: MARKET PENETRATION AND

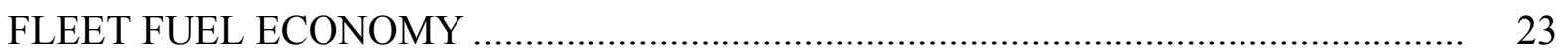

6 RESULTS OF MODELING: OVERALL BENEFITS FOR THE VEHICLE TECHNOLOGIES PROGRAM .................................................................................. 29

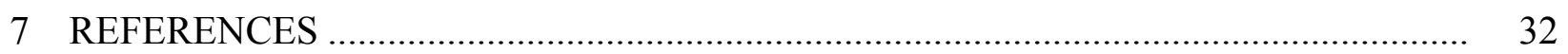

\section{FIGURES}

1 PHEV Battery Cost and Combined Inverter/Motor Cost ………………………….............. 5

2 Efficiency Gains in Passenger Vehicles and Commercial Vehicles.................................... 7

3 Vehicle Structure Weight Reduction ........................................................................... 10

4 Cumulative Miles of PHEV and EV Testing .................................................................. 13 


\section{FIGURES (CONT.)}

5 LDV Market Penetration Estimates for No Program and Target Cases

6 Fleet-Average Fuel Economy of New Cars, Light-Duty Trucks, and LDV Fleet

for the No Program Case and Target Case.

7 Average On-Road Fuel Economy of New Cars, Light-Duty Trucks, and LDV Fleet for the No Program Case and Target Case.

8 Fleet-Average Fuel Economy of Medium- and Heavy-Duty Trucks for the No Program Case and Target Case

\section{TABLES}

1 Vehicle Technologies Program: Assumed Budget Projections

2 Target Benefits of Battery and Electric Drive Technology Subprogram:

Reduced Fuel Consumption per Mile Compared to That of Vehicles

with Same Type of Drivetrain.

3 Target Benefits of Advanced Combustion Engine R\&D Subprogram:

Reduced Fuel Consumption per Mile Compared to That of Vehicles

with Same Type of Drivetrain.

4 Target Benefits of Materials Technology R\&D Subprogram:

Reduced Fuel Consumption per Mile Compared to That of Vehicles

with Same Type of Drivetrain.

5 Target Benefits of Fuels and Lubricant Technologies R\&D Subprogram:

Reduced Fuel Consumption per Mile Compared to That of Vehicles with Same Type of Drivetrain.

6 Target Benefits of Vehicle and Systems Simulation and Testing Subprogram.

7 Target Benefits of Outreach, Deployment, and Analysis Subprogram

8 LDV Market Penetration Estimates for No Program and Target Cases

9 Difference in LDV Market Penetration Estimates between Target and No Program Cases. 


\section{TABLES (CONT.)}

10 Medium- and Heavy-Duty Truck Market Penetration Estimates for the Target Case, as Percentage of VMT

11 Vehicle Technologies Program Benefits Metrics 


\section{NOTATION}

\section{ACRONYMS AND ABBREVIATIONS}

ACE

AEO

BEDT

BEV

BEV100, 200, etc.

CAFE

CI

DOE

EERE

EIA

EPA

FCV

FY

GDP

GHG

GPRA

HCCI

HEV

HT

HTEB

ICE

LDV

$\mathrm{MA}^{3} \mathrm{~T}$

NEMS

OEM

OPEC

ORNL
Advanced Combustion Engine (R\&D subprogram)

Annual Energy Outlook

Battery and Electric Drive Technology (subprogram)

battery electric vehicle

BEV with battery sized for range of 100,200 , etc. miles

Corporate Average Fuel Economy (standards)

compression ignition

U.S. Department of Energy

Office of Energy Efficiency and Renewable Energy

Energy Information Administration

U.S. Environmental Protection Agency

fuel cell vehicle

fiscal year

gross domestic product

greenhouse gas

Government Performance and Results Act

homogeneous charge compression engine

hybrid electric vehicle

heavy-duty truck

Heavy-Truck Energy Balance (model)

internal combustion engine

light-duty vehicle

Market Acceptance of Advanced Automotive Technologies (model)

National Energy Modeling System

original equipment manufacturer

Organization of the Petroleum Exporting Countries

Oak Ridge National Laboratory 
PEEM

PHEV

PHEV20, 20, etc.

R\&D

SI

SUV

VMT

VSST

VTP power electronics and electric motors plug-in hybrid electric vehicle

PHEV with nominal charge-depleting range of 10,20 , etc. miles

research and development

spark ignition

sport utility vehicle

vehicle mile(s) traveled

Vehicle and Systems Simulation and Testing (subprogram)

Vehicle Technologies Program

\section{UNITS OF MEASURE}

$\begin{array}{ll}\begin{array}{l}\text { bbl } \\ \text { bpd }\end{array} & \begin{array}{l}\text { barrel(s) } \\ \text { barrel(s) per day }\end{array} \\ \text { gal } & \text { gallon(s) } \\ \mathrm{kW} & \text { kilowatt(s) } \\ \mathrm{kWh} & \text { kilowatt-hour(s) } \\ \mathrm{mpg} & \text { mile(s) per gallon } \\ \mathrm{t} & \text { metric ton(s) } \\ \mathrm{yr} & \text { year(s) }\end{array}$




\title{
VEHICLE TECHNOLOGIES PROGRAM GOVERNMENT PERFORMANCE AND RESULTS ACT (GPRA) REPORT FOR FISCAL YEAR 2012
}

by

J. Ward, T.S. Stephens, and A.K. Birky

\begin{abstract}
The U.S. Department of Energy's Office of Energy Efficiency and Renewable Energy has defined milestones for its Vehicle Technologies Program (VTP). This report provides estimates of the benefits that would accrue from achieving these milestones relative to a base case that represents a future in which there is no VTP-supported vehicle technology development. Improvements in the fuel economy and reductions in the cost of light- and heavy-duty vehicles were estimated by using Argonne National Laboratory's Autonomie powertrain simulation software and doing some additional analysis. Argonne also estimated the fraction of the fuel economy improvements that were attributable to VTP-supported development in four "subsystem" technology areas: batteries and electric drives, advanced combustion engines, fuels and lubricants, and materials (i.e., reducing vehicle mass, called "lightweighting"). Oak Ridge National Laboratory's MA ${ }^{3} \mathrm{~T}$ (Market Acceptance of Advanced Automotive Technologies) tool was used to project the market penetration of light-duty vehicles, and TA Engineering's TRUCK tool was used to project the penetrations of medium- and heavy-duty trucks. Argonne's VISION transportation energy accounting model was used to estimate total fuel savings, reductions in primary energy consumption, and reductions in greenhouse gas emissions that would result from achieving VTP milestones. These projections indicate that by 2030 , the on-road fuel economy of both light- and heavy-duty vehicles would improve by more than $20 \%$, and that this positive impact would be accompanied by a reduction in oil consumption of nearly 2 million barrels per day and a reduction in greenhouse gas emissions of more than 300 million metric tons of $\mathrm{CO}_{2}$ equivalent per year. These benefits would have a significant economic value in the U.S. transportation sector and reduce its dependency on oil and its vulnerability to oil price shocks.
\end{abstract}




\section{INTRODUCTION AND PROGRAM OVERVIEW}

The Vehicle Technologies Program (VTP or the Program) focuses on research and development (R\&D) to (1) improve the energy efficiency of current cars, light trucks, and heavy vehicles and (2) develop new technologies that will help transition vehicles away from using petroleum fuels. These R\&D activities could result in significant benefits as more hybrid electric vehicles (HEVs), light-weight materials, low-temperature combustion regimes, and alternative fuels are used.

This document describes the "storyline" on how the benefits that could result from the VTP are determined; that is, it describes the methodology used in the program and the context in which the program's current and soon-to-be-implemented R\&D activities get translated into estimates of future benefits. For transportation modes that have long been supported by the U.S. Department of Energy (DOE), the analysis of benefits involves relatively sophisticated models, including advanced computer models, that convert R\&D activities into fuel economy improvement metrics. For transportation modes that have not been supported by DOE (at least, not recently), the analysis of benefits starts with educated assumptions about the potential impacts that the VTP could have within the transportation mode, and then, on the basis of trends that are occurring in that mode and on the near-term impacts from the VTP, estimates potential long-term benefits.

The benefits storyline, which is preceded by a discussion of VTP activities, opens with a discussion of a baseline "No Program" scenario against which to measure Program benefits and of the important factors to consider when using this baseline to make comparisons. The next section discusses vehicle modeling and simulation done by Argonne National Laboratory's Autonomie software, the results of which are attributed to subprograms and key activities by means of a method that is described in the section that immediately follows. The final sections discuss subprogram key activities and tie major goals to specific fuel economy increases or energy use reductions. 


\section{ASSUMED BUDGET PROJECTIONS}

Because a fiscal year 2012 (FY12) budget had not been finalized at the time of this analysis, this report assumes that VTP budget levels will remain flat, at FY11-appropriated levels, through 2016, the last year through which targets and goals have been set for many key activities. A breakdown of this budget, by subprogram, is shown in Table 1.

TABLE 1 Vehicle Technologies Program: Assumed Budget Projections

\begin{tabular}{|c|c|c|c|c|c|c|}
\hline \multirow[b]{2}{*}{ Activity } & \multicolumn{6}{|c|}{ Funding $(\$ \times 1000)$ per Fiscal Year } \\
\hline & FY11 & FY12 & FY13 & FY14 & FY15 & FY16 \\
\hline Batteries and electric drive technology & 103,163 & 103,163 & 103,163 & 103,163 & 103,163 & 103,163 \\
\hline Advanced combustion engine $R \& D$ & 55,987 & 55,987 & 55,987 & 55,987 & 55,987 & 55,987 \\
\hline Materials technology R\&D & 47,748 & 47,748 & 47,748 & 47,748 & 47,748 & 47,748 \\
\hline Fuels and lubricant technologies R\&D & 10,692 & 10,692 & 10,692 & 10,692 & 10,692 & 10,692 \\
\hline $\begin{array}{l}\text { Vehicle and systems simulation and } \\
\text { testing }\end{array}$ & 42,647 & 42,647 & 42,647 & 42,647 & 42,647 & 42.647 \\
\hline Outreach, deployment, and analysis & 32,914 & 32,914 & 32,914 & 32,914 & 32,914 & 32,914 \\
\hline Total & 293,151 & 293,151 & 293,151 & 293,151 & 293,151 & 293,151 \\
\hline
\end{tabular}




\section{PROGRAM ACTIVITIES, MILESTONES, AND OUTPUTS}

In FY12, the VTP will continue to focus on the following technology areas and activities (i.e., subprograms):

1. Batteries and Electric Drive Technology (BEDT);

2. Advanced Combustion Engine (ACE) R\&D;

3. Materials Technology R\&D;

4. Fuels and Lubricant Technologies R\&D;

5. Vehicle and Systems Simulation and Testing (VSST); and

6. Outreach, Deployment, and Analysis.

For each of these technology areas/activities, DOE's Office of Energy Efficiency and Renewable Energy (EERE) has established milestones. Achieving these milestones in the first four subprogram areas will significantly improve vehicle technologies and increase the fuel efficiency of light-duty vehicles (LDVs) and medium- and heavy-duty trucks. The success and deployment of these technologies will depend on the last two subprogram areas. The rest of Section 3 briefly describes the milestones for each subprogram area and the estimated benefits that could result from their achievement.

With regard to the first four technology areas, the contribution of each to achieving the milestones was estimated as the fraction of decrease in fuel consumption per mile by new vehicles, for each vehicle type, achieved due to the technology improvements to be made in that area (assuming program success). In the tables that follow here in Sections 3.1 through 3.4, these decreased fuel consumption fractions are shown as percentages of the fuel consumed per mile by the baseline vehicle that has the same type of drivetrain as the new vehicle (1) in the same year that it was manufactured and (2) in the year 2010. These percentages were estimated from (1) component-level vehicle characteristics used in the Autonomie model for LDVs and (2) power flows used in the Heavy-Truck Energy Balance (HTEB) model for medium- and heavy-duty trucks (as described in Section 4).

\subsection{BATTERIES AND ELECTRIC DRIVE TECHNOLOGY}

The Battery and Electric Drive Technology (BEDT) subprogram addresses the use of electric energy storage, electric drives, and energy recovery in new, more efficient vehicle designs. The subprogram funds R\&D on the core technologies needed for hybrid electric vehicles (HEVs) and electric vehicles to achieve significant improvements in fuel economy without sacrificing safety, environmental benefits, vehicle performance, or vehicle affordability (i.e., purchase price and cost to operate and maintain). Efforts aim to reduce the production cost of a high-energy battery from $\$ 1,000 / \mathrm{kWh}$ in 2008 to $\$ 300 / \mathrm{kWh}$ by 2014 (thereby enabling the cost-competitive market entry of plug-in HEVs [PHEVs]) and to reduce the cost of an electrictraction-drive system that can deliver $55 \mathrm{~kW}$ of peak power for 18 seconds and $30 \mathrm{~kW}$ of continuous power from $\$ 22 / \mathrm{kW}$ in 2008 to $\$ 12 / \mathrm{kW}$ in 2015 (thereby enabling the costcompetitive market entry of PHEVs and HEVs); see Figure 1. 

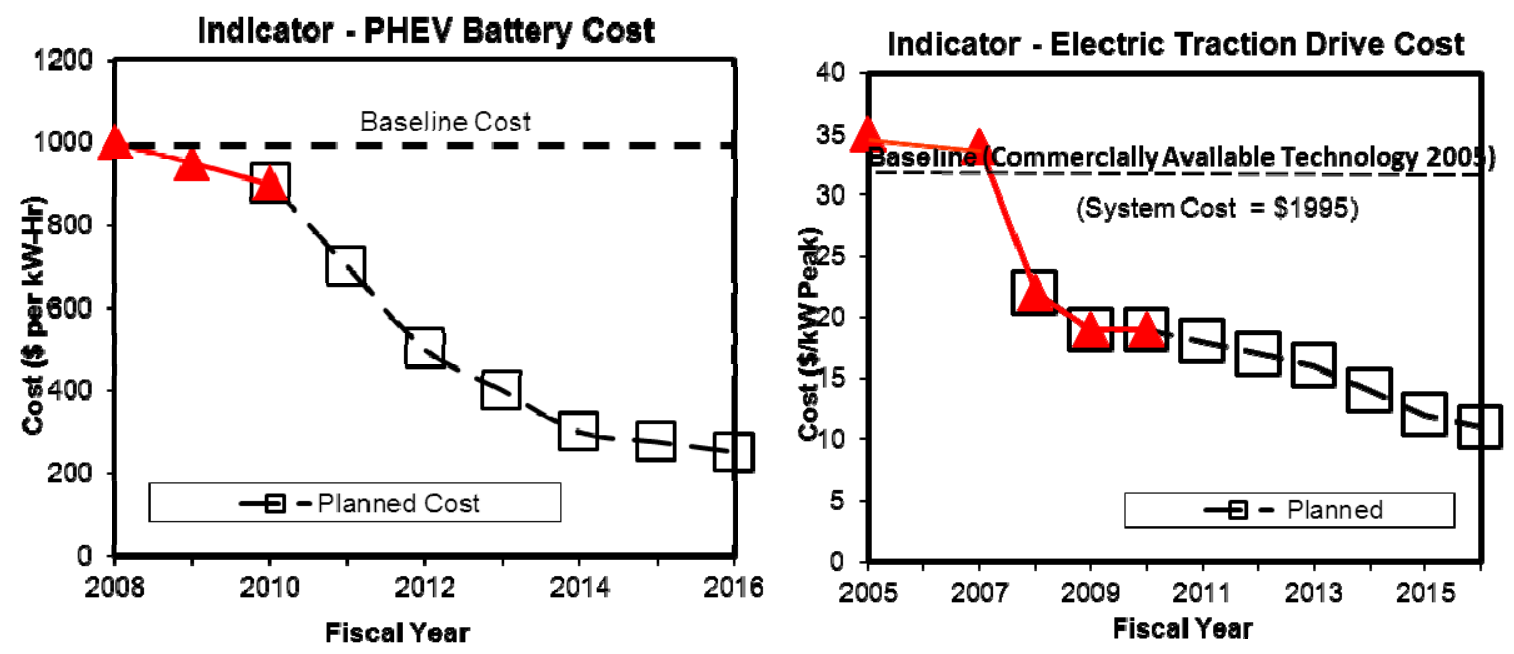

FIGURE 1 PHEV Battery Cost and Combined Inverter/Motor Cost

In FY12, the BEDT subprogram will continue to accelerate the development of low-cost, high-energy batteries and the corresponding improvements in electric-drive systems (motors, power electronics, and electric controls) that are needed to make PHEVs cost effective. PHEVs have the potential to provide significant additional fuel savings, particularly when it comes to commuter and local driving, over the savings achieved by either combustion-powered or fuelcell-powered hybrid passenger vehicles.

In Table 2, the improvements (decrease) in fuel consumption per mile achieved by new vehicles having each type of drivetrain that are attributable to VTP work with batteries and electric-drive technology are shown for the years 2030 and 2050. In the first (top) row, the improvement over the baseline (No Program) vehicle of the same drivetrain type is shown, and in the second (bottom) row, the improvement over the year 2010 baseline vehicle of the same drivetrain type is shown. (In this table and throughout document, SI refers to spark ignition, CI refers to compression ignition, PHEV20 refers to a PHEV with a nominal charge-depleting range of 20 miles, HT refers to a heavy-duty truck, and VMT refers to vehicle miles traveled.)

\subsection{ADVANCED COMBUSTION ENGINE R\&D}

The Advanced Combustion Engine (ACE) R\&D subprogram focuses on removing critical technical barriers to commercializing more efficient, advanced internal combustion engines (ICEs) for passenger and commercial vehicles. Increasing the efficiency of ICEs is one of the most cost-effective approaches for reducing the amount of petroleum consumed by the nation's fleet of vehicles in the near- to mid-term. Using these advanced engines in HEVs and PHEVs would enable even greater fuel savings. Improvements in engine efficiency alone have the potential to dramatically increase vehicle fuel economy and reduce greenhouse (GHG) emissions. The aim of accelerated research on advanced combustion regimes - including homogeneous charge compression ignition (HCCI) and other modes of low-temperature 
TABLE 2 Target Benefits of Battery and Electric Drive Technology Subprogram: Reduced Fuel Consumption per Mile Compared to That of Vehicles with Same Type of Drivetrain

\begin{tabular}{|c|c|c|c|c|c|c|c|c|c|c|c|}
\hline \multirow[b]{3}{*}{ Key Focus } & \multirow[b]{3}{*}{ Metric } & \multicolumn{10}{|c|}{ New Vehicle Fuel Economy Impact $(\%)^{\mathrm{a}}$} \\
\hline & & \multicolumn{2}{|c|}{ SI } & \multicolumn{2}{|c|}{$\mathrm{CI}$} & \multicolumn{2}{|c|}{$\mathrm{HEV}$} & \multicolumn{2}{|c|}{ PHEV20 } & \multicolumn{2}{|c|}{ HT } \\
\hline & & 2030 & 2050 & 2030 & 2050 & 2030 & 2050 & 2030 & 2050 & 2030 & 2050 \\
\hline \multirow[t]{2}{*}{$\begin{array}{l}\text { Energy storage, power } \\
\text { electronics, and } \\
\text { electric motors }\end{array}$} & $\begin{array}{l}\text { Relative to } \\
\text { baseline vehicle } \\
\text { in the same year }\end{array}$ & - & - & - & - & 3.8 & 3.2 & 1.5 & 1.0 & 1.6 & 2.7 \\
\hline & $\begin{array}{l}\text { Relative to } \\
\text { baseline vehicle } \\
\text { in year } 2010\end{array}$ & - & - & - & - & 6.2 & 7.0 & 2.4 & 3.3 & 1.6 & 2.7 \\
\hline
\end{tabular}

${ }^{a}$ The fuel economy impact is the decrease in fuel consumption per mile due to DOE-sponsored improvements in batteries and electric drive technology in a new vehicle over a baseline vehicle having the same type of drivetrain in that year (top row) or in the year 2010 (bottom row). HT percentages are VMTand sales-weighted average improvements. These projections are mere estimations and can change with new DOE or DOE-sponsored research activities. 
combustion, lean-burn gasoline, and multi-fuel operation - is to realize this potential. ACE subprogram goals are to (1) increase the efficiency of LDV ICEs by improving the fuel economy of a 2015 gasoline vehicle so it is $25 \%$ better than that of a 2009 baseline vehicle; (2) increase the efficiency of commercial vehicle ICEs by demonstrating a fuel economy improvement of $20 \%$ in 2015 vehicles and 30\% in 2020 vehicles over the fuel consumption in 2009 baseline vehicles (Figure 2); and (3) increase the efficiency of thermoelectric generators in converting waste heat to electricity from $8 \%$ in 2011 to more than $15 \%$ in 2015 .

In FY12, in the area of combustion and emission controls, funding will continue for four cooperative agreements awarded in FY10 for passenger vehicle advanced powertrain systems that were not funded through the American Recovery and Reinvestment Act. The agreements aim to demonstrate a $25-40 \%$ improvement in vehicle fuel economy by 2015 . In this area, work will also continue on six awards given to universities to conduct research on combustion and develop emission control systems for advanced engines. In the area of solid-state energy conversion, the focus will be on pursuing cost-shared, cooperative agreements (typically three to five years long) with industries and academia to develop and fabricate (1) high-efficiency thermoelectric generators to produce electricity from waste heat and (2) thermoelectric air conditioners/heaters to replace current R134-a gas air conditioners in passenger and commercial vehicles. Efforts will also be made to investigate scaling up the production of thermoelectric modules that could be demonstrated in vehicle applications and that have the potential to improve vehicle fuel economy by up to $5 \%$ in 2015 . A collaboration with the National Science Foundation to fund thermoelectric projects at several universities will also continue to be supported. Finally, research on advanced thermoelectric materials and their scale-up for demonstration in vehicle applications will also continue.
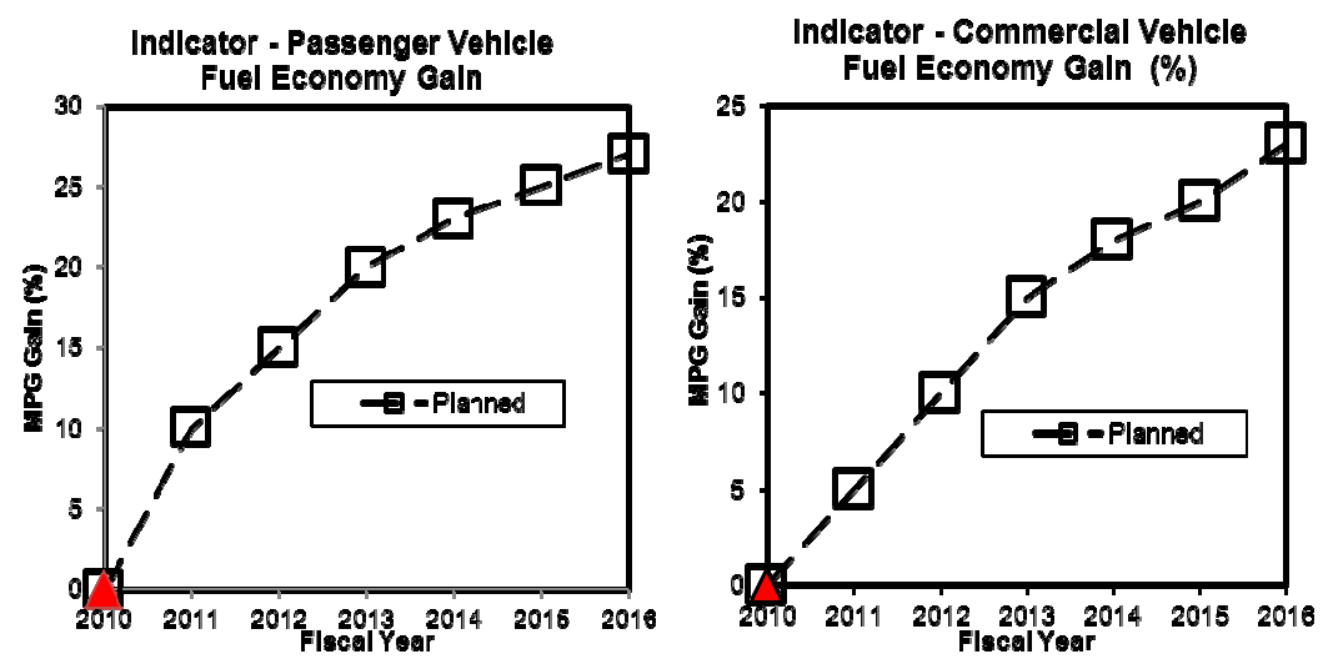

FIGURE 2 Efficiency Gains in Passenger Vehicles (left) and Commercial Vehicles (right) 
In Table 3, the improvements (decrease) in fuel consumption per mile achieved by new vehicles of each drivetrain type that are attributable to VTP efforts on combustion technology are shown for the years 2030 and 2050. In the first (top) row, the improvement over the baseline (No Program) vehicle of the same drivetrain type is shown, and in the second (bottom) row, the improvement over the year 2010 baseline vehicle of the same drivetrain type is shown.

\subsection{MATERIALS TECHNOLOGY R\&D}

The Materials Technology R\&D subprogram develops higher-performing, more costeffective materials that will make lighter vehicle structures and more efficient power systems. Lighter vehicles require less energy to operate and thus reduce fuel consumption. Likewise, better propulsion materials can enable power systems to be more efficient, which contributes to a vehicle's reduced energy consumption. For a mid-sized or larger vehicle, every $10 \%$ reduction in a vehicle's weight can result in a 6-8\% increase in its fuel economy (see Figure 3).

In FY12, research efforts will support three VTP teams - (1) advanced combustion engines, (2) fuels, and (3) hybrid electric systems - to achieve energy efficiency improvements and petroleum displacement goals. Much of the materials work will support diesel engines, because they currently operate at much higher efficiencies and pressures than do gasoline engines, and will provide insights on the materials-related hurdles confronting engine designers as they strive to achieve the higher peak cylinder pressures necessary for improved thermal efficiency. Researchers will use specialized characterization and processing techniques to develop materials for in-cylinder thermal management, friction reduction, improved dynamic response, increased peak cylinder pressure, and increased power-to-weight ratios that support the development of high-efficiency, advanced combustion engines. In cooperation with the VTP fuels team, researchers will identify and mitigate issues related to the interaction between new fuel formulations and engine component materials. Materials will be developed to improve the performance of energy recovery systems, such as turbo-compounding and solid-state thermoelectric devices. Efforts to develop materials for hybrid- and electric-drive components will target cost-effective domestic magnetic materials for drive motors and high-temperature power electronics. All activities will have technology transfer components to communicate results to industry, thereby accelerating the deployment of beneficial technologies. In addition, funding in this area may be used to support various efforts such as peer reviews; data collection and dissemination; and technical, market, economic, and other analyses.

In Table 4, the improvements (decrease) in fuel consumption per mile achieved by new vehicles having each type of drivetrain that are attributable to VTP work with materials technology are shown for the years 2030 and 2050. In the first (top) row, the improvement over the baseline (No Program) vehicle of the same drivetrain type is shown, and in the second (bottom) row, the improvement over the year 2010 baseline vehicle of the same drivetrain type is shown. 
TABLE 3 Target Benefits of Advanced Combustion Engine R\&D Subprogram: Reduced Fuel Consumption per Mile Compared to That of Vehicles with Same Type of Drivetrain

\begin{tabular}{|c|c|c|c|c|c|c|c|c|c|c|c|}
\hline \multirow[b]{3}{*}{ Key Focus } & \multirow[b]{3}{*}{ Metric } & \multicolumn{10}{|c|}{ New Vehicle Fuel Economy Impact $(\%)^{\mathrm{a}}$} \\
\hline & & \multicolumn{2}{|c|}{ SI } & \multicolumn{2}{|c|}{$\mathrm{CI}$} & \multicolumn{2}{|c|}{$\mathrm{HEV}$} & \multicolumn{2}{|c|}{ PHEV20 } & \multicolumn{2}{|c|}{ HT } \\
\hline & & 2030 & 2050 & 2030 & 2050 & 2030 & 2050 & 2030 & 2050 & 2030 & 2050 \\
\hline \multirow[t]{2}{*}{$\begin{array}{l}\text { Combined } \\
\text { combustion portfolio }\end{array}$} & $\begin{array}{l}\text { Relative to } \\
\text { baseline vehicle } \\
\text { in the same year }\end{array}$ & 10.4 & 8.1 & 3.6 & 5.3 & 3.8 & 3.2 & 1.5 & 1.0 & 13.5 & 13.3 \\
\hline & $\begin{array}{l}\text { Relative to } \\
\text { baseline vehicle } \\
\text { in year } 2010\end{array}$ & 20.8 & 25.5 & 7.0 & 10.7 & 6.2 & 7.0 & 2.4 & 3.3 & 13.9 & 14.0 \\
\hline
\end{tabular}

${ }^{a}$ Fuel economy impact is the decrease in fuel consumption per mile due to DOE-sponsored improvements in combustion engine technology in a new vehicle over a baseline vehicle having the same type of drivetrain in that year (top row) or in the year 2010 (bottom row). HT percentages are VMT- and sales-weighted average improvements. These projections are mere estimations and can change with new DOE or DOE-sponsored research activities. 


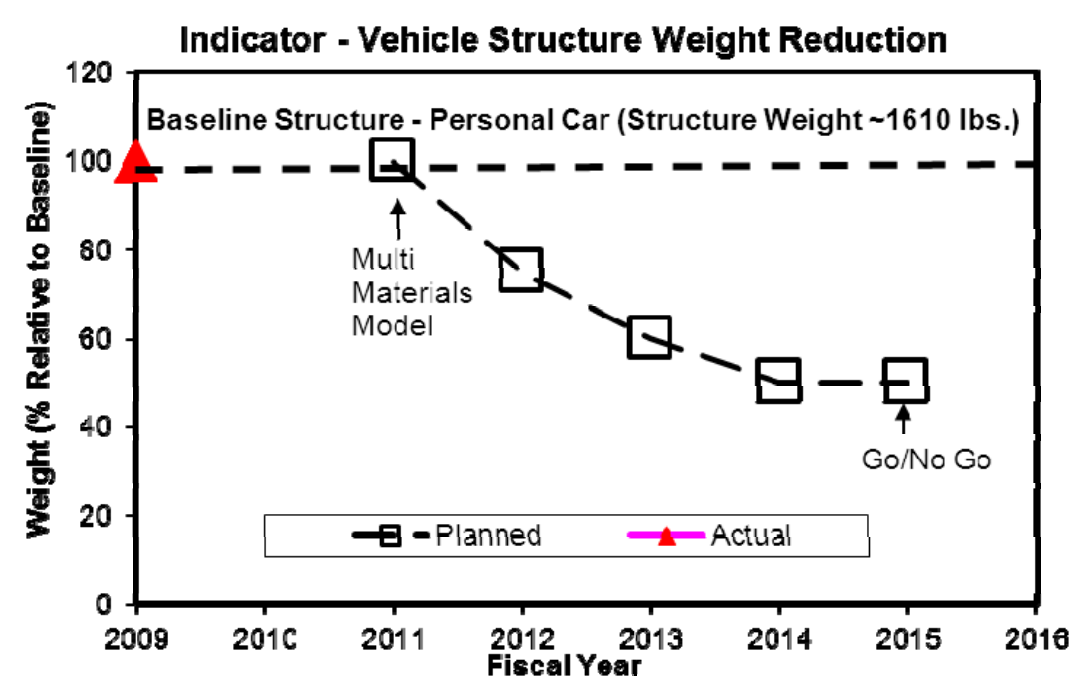

FIGURE 3 Vehicle Structure Weight Reduction

\subsection{FUELS AND LUBRICANT TECHNOLOGIES R\&D}

The Fuels and Lubricant Technologies R\&D subprogram evaluates the advanced fuels, fuel components, and lubricants that are used or proposed for use in current and advanced engines. Fuels of interest range from pure alternative fuels to fuels containing mixtures of conventional and unconventional components (e.g., butanol or green diesel). Biomass-based renewable fuels and bio-synthetic fuels are emphasized. Specific areas being investigated include fuel quality and stability; the detailed chemical composition of a fuel and its relationship to fuel bulk properties; the effects of physical and chemical properties on engine performance and emissions; and safety associated with storage, handling, and toxicity.

In FY12, studies will continue on the effects of variations in physical and chemical properties of renewable and alternative fuels on the performance and emissions of advanced combustion engines. This work will be undertaken in close coordination with the ACE R\&D subprogram. In addition, studies of next-generation biomass-derived transportation fuels will be expanded into a comprehensive $\mathrm{R} \& \mathrm{D}$ and testing program to assess the feasibility of the largescale deployment of such fuels. In FY12, a comprehensive study of advanced lubricants for increased efficiency will also begin.

In Table 5, the improvements (decrease) in fuel consumption per mile achieved by new vehicles of each drivetrain type that are attributable to VTP work with fuel and lubricant technologies are shown for the years 2030 and 2050. In the first (top) row, the improvement over the baseline (No Program) vehicle of the same drivetrain type is shown, and in the second (bottom) row, the improvement over the year 2010 baseline vehicle of the same drivetrain type is shown. 
TABLE 4 Target Benefits of Materials Technology R\&D Subprogram: Reduced Fuel Consumption per Mile Compared to That of Vehicles with Same Type of Drivetrain

\begin{tabular}{|c|c|c|c|c|c|c|c|c|c|c|c|}
\hline \multirow[b]{3}{*}{ Key Focus } & \multirow[b]{3}{*}{ Metric } & \multicolumn{10}{|c|}{ New Vehicle Fuel Economy Impact (\%) } \\
\hline & & \multicolumn{2}{|c|}{ SI } & \multicolumn{2}{|c|}{$\mathrm{CI}$} & \multicolumn{2}{|c|}{$\mathrm{HEV}$} & \multicolumn{2}{|c|}{ PHEV20 } & \multicolumn{2}{|c|}{ HT } \\
\hline & & 2030 & 2050 & 2030 & 2050 & 2030 & 2050 & 2030 & 2050 & 2030 & 2050 \\
\hline \multirow[t]{2}{*}{$\begin{array}{l}\text { Propulsion and } \\
\text { structural materials }\end{array}$} & $\begin{array}{l}\text { Relative to } \\
\text { baseline vehicle in } \\
\text { the same year }\end{array}$ & 8.1 & 7.5 & 6.8 & 7.0 & 7.3 & 3.9 & 7.5 & 6.4 & 0.2 & 0.3 \\
\hline & $\begin{array}{l}\text { Relative to } \\
\text { baseline vehicle in } \\
\text { year } 2010\end{array}$ & 6.7 & 7.2 & 6.2 & 6.7 & 6.0 & 6.6 & 5.8 & 6.3 & 0.2 & 0.3 \\
\hline
\end{tabular}

${ }^{a}$ The fuel economy impact is decrease in fuel consumption per mile due to DOE-sponsored improvements in propulsion and structural technologies that enable lighter weights in a new vehicle over a baseline vehicle having the same type of drivetrain in that year (top row) or in the year 2010 (bottom row). HT percentages are VMT- and sales-weighted average improvements. These projections are mere estimations and can change with new DOE or DOEsponsored research activities. 
TABLE 5 Target Benefits of Fuels and Lubricant Technologies R\&D Subprogram: Reduced Fuel Consumption per Mile Compared to That of Vehicles with Same Type of Drivetrain

\begin{tabular}{|c|c|c|c|c|c|c|c|c|c|c|c|}
\hline \multirow[b]{3}{*}{ Key Focus } & \multirow[b]{3}{*}{ Metric } & \multicolumn{10}{|c|}{ New Vehicle Fuel Economy Impact (\%) ${ }^{\mathrm{a}}$} \\
\hline & & \multicolumn{2}{|c|}{ SI } & \multicolumn{2}{|c|}{$\mathrm{CI}$} & \multicolumn{2}{|c|}{$\mathrm{HEV}$} & \multicolumn{2}{|c|}{ PHEV20 } & \multicolumn{2}{|c|}{ HT } \\
\hline & & 2030 & 2050 & 2030 & 2050 & 2030 & 2050 & 2030 & 2050 & 2030 & 2050 \\
\hline \multirow[t]{2}{*}{$\begin{array}{l}\text { Fuels and lubricant } \\
\text { technologies }\end{array}$} & $\begin{array}{l}\text { Relative to } \\
\text { baseline vehicle } \\
\text { in the same year }\end{array}$ & 0.9 & 1.2 & 0.9 & 1.2 & 0.9 & 1.2 & 1.0 & 1.2 & $\mathrm{~N} / \mathrm{E}$ & $\mathrm{N} / \mathrm{E}$ \\
\hline & $\begin{array}{l}\text { Relative to } \\
\text { baseline vehicle } \\
\text { in year } 2010\end{array}$ & 0.7 & 1.1 & 0.8 & 1.1 & 0.7 & 1.1 & 0.7 & 1.1 & $\mathrm{~N} / \mathrm{E}$ & $\mathrm{N} / \mathrm{E}$ \\
\hline
\end{tabular}

${ }^{a}$ The fuel economy impact is the decrease in fuel consumption per mile due to DOE-sponsored improvements in lubricant and friction-reduction technologies in a new vehicle over a baseline vehicle having the same type of drivetrain in that year (top row) or in the year 2010 (bottom row). HT percentages are VMT- and sales-weighted average improvements. These projections are mere estimations and can change with new DOE or DOE-sponsored research activities. N/E = not estimated. 


\subsection{VEHICLE AND SYSTEMS SIMULATION AND TESTING}

Vehicle and Systems Simulation and Testing (VSST) integrates the modeling, systems analysis, vehicle testing and evaluation, codes and standards development, and systems optimization efforts that support VTP. The key program activity is to use a systems approach to define technical targets and requirements, guide technology development, and validate the performance of VTP-sponsored technologies for passenger and commercial vehicles. To accomplish these objectives, during VSST, models and simulation tools are developed and validated to predict the performance, component interaction, fuel economy, and emissions of advanced vehicles. With industry input, the models are used to develop (1) performance targets for the complete range of vehicle platforms and their components; (2) advanced control strategies to optimize the interactions between components and the overall performance and efficiency of advanced HEVs, PHEVs, electric vehicles, and fuel cell vehicles (FCVs); and (3) data on advanced vehicle performance and characteristics, which are then used to predict market potential and petroleum displacement; these predictions, in turn, help guide VTP-wide research.

FY 2012 VSST activities will support the modeling of advanced electric-drive vehicles and systems, as well as the baseline testing and evaluation of both commercial and passenger electric-drive vehicles, in cooperation with manufacturers, utilities, and other industry partners. Laboratory and field evaluations of advanced prototype and pre-production electric-drive vehicles with dual energy storage systems and other advanced energy storage devices, electric motors, and power electronics will be conducted. The VSST activities will also include research on heavy vehicle systems to develop models and R\&D on technologies that will reduce nonengine-related, parasitic energy losses from aerodynamic drag, friction and wear, under-hood thermal conditions, accessory loads, and tires. Program plans are to complete more than 100 million miles of test activities before 2015, as shown in Figure 4.

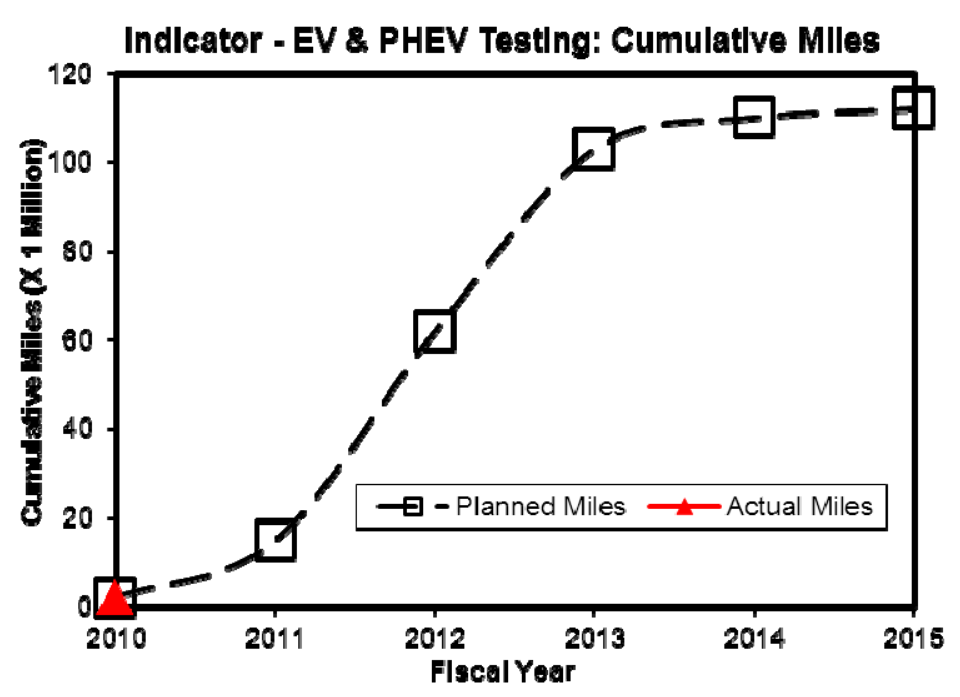

FIGURE 4 Cumulative Miles of PHEV and EV Testing 
In Table 6, no fuel economy impact values are shown, but the simulation and testing activities are critical to other subprograms.

\subsection{OUTREACH, DEPLOYMENT, AND ANALYSIS}

The Outreach, Deployment, and Analysis subprogram contributes directly to VTP's benefits to the climate by accelerating the movement of advanced technologies into widespread use. With regard to the existing program, the university-based activities contribute to a "green" workforce, who will incorporate a consideration of energy efficiency into their projects throughout their entire careers, and the deployment activities directly accelerate the movement of advanced-technology vehicles into the marketplace.

FY12 funding for vehicle technologies deployment will focus on expanding activities dedicated to electric-drive vehicle deployment and related infrastructure development, in support of the President's goal to put 1 million electric vehicles on the road by 2015. This competitive grant program will support communities that become early adopters of electric-drive vehicles through regulatory streamlining, infrastructure planning and development, and other investments. FY12 funding will also support graduate education on automotive technology, advanced vehicle competitions for students, legislative and rulemaking activities, and studies on reducing VMT and improving legacy fleets.

In Table 7, no fuel economy impact values are shown, but the outreach, deployment, and analysis activities are critical to achieving market penetration of technologies developed under the other subprograms. 
TABLE 6 Target Benefits of Vehicle and Systems Simulation and Testing Subprogram

New Vehicle Fuel Economy Impact

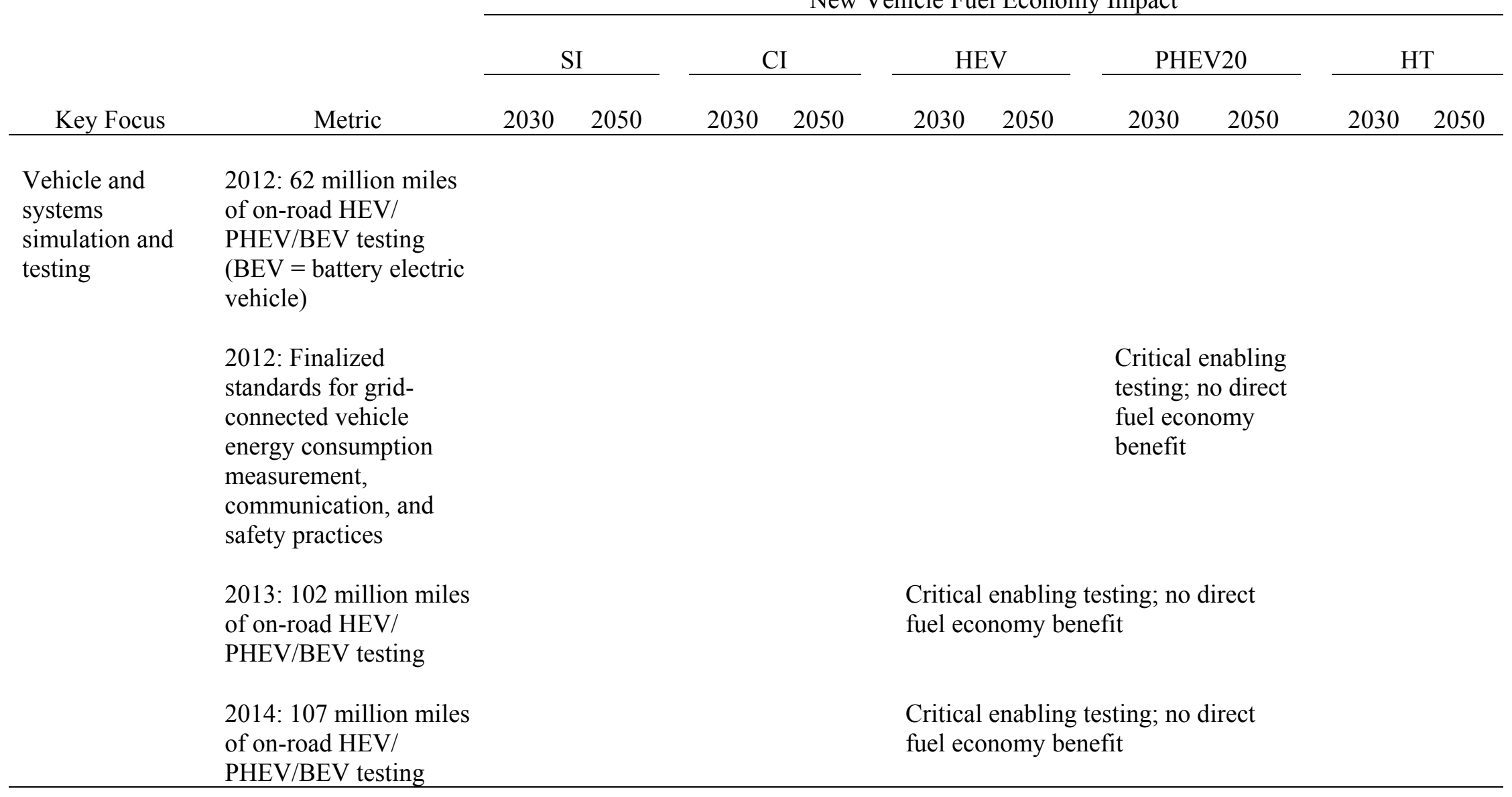


TABLE 7 Target Benefits of Outreach, Deployment, and Analysis Subprogram

\begin{tabular}{|c|c|c|c|c|c|c|c|c|c|c|c|}
\hline \multirow[b]{3}{*}{ Key Focus } & \multirow[b]{3}{*}{ Metric } & \multicolumn{10}{|c|}{ New Vehicle Fuel Economy Impact (gal/yr) } \\
\hline & & \multicolumn{2}{|c|}{ SI } & \multicolumn{2}{|c|}{$\mathrm{CI}$} & \multicolumn{2}{|c|}{$\mathrm{HEV}$} & \multicolumn{2}{|c|}{ PHEV20 } & \multicolumn{2}{|c|}{ HT } \\
\hline & & 2030 & 2050 & 2030 & 2050 & 2030 & 2050 & 2030 & 2050 & 2030 & 2050 \\
\hline \multirow[t]{3}{*}{ Clean cities } & 2012: Petroleum reduction & \multicolumn{10}{|c|}{700 million (various vehicle platforms) } \\
\hline & 2014: Petroleum reduction & \multicolumn{10}{|c|}{900 million (various vehicle platforms) } \\
\hline & 2015: Petroleum reduction & \multicolumn{10}{|c|}{1 billion (various vehicle platforms) } \\
\hline
\end{tabular}

These projections are mere estimations and can change with new DOE or DOE-sponsored partner activities. 


\section{TRANSLATING PROGRAM GOALS INTO ENERGY MODEL INPUT PARAMETERS}

\subsection{BASELINE "NO PROGRAM" CASE}

Benefits were calculated as reductions in energy use, fuel use, GHG emissions, and consumer expenditures from the baseline "No Program" case. The No Program case was developed to represent future vehicle technology, fuel use, and GHG emissions without the effects of VTP technology improvements. The DOE Energy Information Administration's (EIA's) Annual Energy Outlook (AEO) is the most widely recognized DOE-wide projection and analysis of future U.S. energy supplies, demands, and prices. As such, it is an obvious choice for a baseline against which to compare an energy future enriched by DOE programs. However, the EIA's AEO reference case assumes that current policies remain in effect, and projections made in the AEO reference case thus incorporate assumptions about the market success of technologies historically supported by the VTP and the assumption that there will be continued support. This AEO reference case is therefore not an appropriate one to use for the baseline No Program case. An appropriate baseline case that projects the reduced technological progress over time that is expected to occur without VTP-supported R\&D must be constructed for both LDVs and heavy trucks.

For LDVs, a baseline case was developed based on Autonomie simulations of future vehicles by assuming that only incremental technology improvements would occur and that there would be no support from the VTP; associated data on vehicle performance, prices, and other attributes were generated for the years 2010,2015, 2020, 2030, and 2045. This baseline case was developed based on assumptions about future vehicle characteristics under current 2011 Corporate Average Fuel Economy (CAFE) standards; that is, CAFE standards proposed for the years 2017 through 2025 were not considered in developing the baseline. The Market Acceptance of Advanced Automotive Technologies (MA $\left.{ }^{3} \mathrm{~T}\right)$ vehicle choice model developed by Oak Ridge National Laboratory (ORNL; Lin and Greene 2010, 2011) was used to make projections of vehicle sales for the baseline case, and these sales shares were used as input for Argonne's VISION model (Ward et al. 2008) to calculate future energy consumption by LDVs for the baseline case.

The baseline case for heavy-duty vehicles was developed by adjusting the new heavy vehicle fuel economies in the AEO 2011 reference case to remove the benefits attributed to the projected penetration of advanced technologies supported by DOE funding. The EIA provided reference case data on the market penetrations of component technologies for heavy trucks that were included in the National Energy Modeling System (NEMS) fuel economy calculations. The contribution of DOE-supported technologies to new fleet fuel economy was then removed by using AEO 2011 reference case input assumptions about the incremental improvements in truck fuel economy due to these component technologies. The resulting adjusted new fleet fuel economies were used as input to the VISION model to calculate future energy consumption by in-use heavy trucks for the baseline case. 
The projections of fuel prices from the AEO 2011 reference case were extrapolated to the year 2050, with the annual rate of increase continued based on the 2030-2035 average slope, and these prices were used in all cases analyzed. Likewise, total vehicle sales were assumed to be the same as in the AEO 2011 reference case, extrapolated to 2050 (a linear extrapolation based on the 2030-2035 average slope).

\subsection{GPRA ADVANCED TECHNOLOGY MODELING}

In general, the analysis of advanced technologies is a market-based approach that requires three steps. First, the Autonomie vehicle simulation model is used to estimate the average fuel economy and incremental cost of new vehicles that incorporate DOE-supported technologies. Second, consumer choice models are used to estimate the market share of these platforms in future years. Finally, the projected fuel economies and market shares are used as inputs to the VISION model, which projects future in-use vehicle stock and estimates fuel consumption. This section provides details on this methodology applied specifically to the lightduty and heavy-duty vehicle markets.

Attributes of light-duty passenger vehicles and medium- and heavy-duty trucks were estimated for the years 2010, 2015, 2020, 2030, and 2045 by using Autonomie, with inputs based on experts from DOE and Argonne's original equipment manufacturer (OEM) partners. Autonomie simulations were run for two cases:

1. "No Program" case, which assumes there is no technology improvement or cost reduction due to the DOE VTP, as described above, and

2. "Target" case, which assumes that there are technology improvements and cost reductions that meet VTP goals.

For each case, starting assumptions about vehicle dimensions, weight, performance, and component characteristics were calculated based on the averages of the sum total of current relevant vehicle data available in the Autonomie library. These assumptions did not take into account CAFE standards proposed for the years 2017 through 2025.

In the first phase of GPRA LDV modeling, Autonomie was used to simulate five vehicle classes - compact car, midsize car, compact sport utility vehicle (SUV), midsize SUV, and pickup truck, with each one having various types of drivetrains, including these:

- Conventional spark ignition (Conv SI);

- Conventional compression ignition (Conv $\mathrm{CI}$ );

- Hybrid electric (HEV);

- Plug-in hybrid electric, with nominal charge-depleting ranges of 10, 20, and 40 miles (PHEV10, PHEV20, PHEV40); 
- Hydrogen internal combustion engine (H2 ICE);

- Hydrogen fuel cell (FCV); and

- Battery electric, with batteries sized for ranges of 100 and 200 miles (BEV100, BEV200).

For each of the preceding powertrain architectures, the Autonomie model converted families of component-level input parameters (intended to describe component technologies at various points in the future for each technology scenario) to a virtual vehicle (appropriately sized to offer sufficient power, given vehicle weight and drivability requirements) and simulated that vehicle's fuel economy over city and highway drive schedules prescribed by the U.S. Environmental Protection Agency (EPA). These simulations resulted in estimates of fuel economy for each vehicle class/drivetrain type. The incremental costs associated with the fuel economy benefits offered by advanced powertrains were calculated by using a combination of direct inputs from programs for advanced technologies and of third-party (Ricardo Engineering)estimated costs for near-commercial technologies. Specifically, EERE cost targets were used to estimate costs for the Target case for batteries, power electronics and electric motors, fuel cells, and on-board hydrogen storage; cost models developed by the Argonne Autonomie group and by Ricardo Engineering were used for estimating costs for other components.

Once Autonomie modeling was complete, outputs were fed as inputs to the $\mathrm{MA}^{3} \mathrm{~T}$ vehicle choice model in the second phase of GPRA LDV modeling. For each of No Program and Target case, sales shares of LDVs having each type of drivetrain were estimated for cars and light trucks by using the $\mathrm{MA}^{3} \mathrm{~T}$ vehicle choice model. This model predicts sales shares each year to 2050 based on vehicle attributes for cars and light trucks. The model takes into account consumer preferences and attributes (based on survey and demographic data), vehicle prices, operating costs, and other attributes to estimate purchase probability for each vehicle type, which are taken to represent sales shares. In $\mathrm{MA}^{3} \mathrm{~T}$, size classes are aggregated (i.e., only one size class each for cars and light trucks is represented), so attributes of midsize sedans were used for cars and attributes of pickup trucks were used for light trucks. Flex-fuel and natural-gas-fueled vehicles were not modeled in $\mathrm{MA}^{3} \mathrm{~T}$.

In the third phase of GPRA LDV modeling, after sales shares were calculated by the $\mathrm{MA}^{3} \mathrm{~T}$ model, the sales shares and fuel economy of each LDV having each type of drivetrain were used as input to the VISION model for both the No Program and Target cases. The VISION model is an accounting spreadsheet that calculates output metrics of interest on a national scale; by comparing the Target and No Program cases, it calculates petroleum savings and GHG reductions.

The sales shares, fuel economy, and retail price equivalent of each LDV having each type of drivetrain were used as input for the VISION model, for both the No Program and Target cases. Not all vehicle types modeled in $\mathrm{MA}^{3} \mathrm{~T}$ are represented individually in the VISION model, so some vehicle types were combined. SI PHEVs were combined into a single PHEV with a charge-depleting range equal to the sales-weighted average of PHEVs with charge-depleting ranges of 10, 20, and 40 miles. Similarly, BEVs were represented as a BEV with a range equal to the sales-weighted average of 100- and 150-mile ranges. 
Fuel economy improvements were attributed to VTP subprogram technologies (batteries and electric drives, advanced combustion, advanced materials, and fuels and lubricant technologies) by estimating the decrease in fuel consumption per mile in advanced vehicles due to improvements in technologies in each VTP area. Decreases in fuel consumption from "lightweighting" (reducing the mass of the vehicle) were attributed to the materials technology used. The difference in the vehicle masses in Autonomie simulations for the Target and No Program cases were used to estimate the fuel saved by lightweighting. For HEVs and PHEVs, changes in the masses of batteries and of power electronics and electric motors (PEEM) were not considered to be part of lightweighting, since the reduction in the masses of these components is attributed to the batteries and electric drive technologies used. It was assumed that the percent decrease in fuel consumption per mile was proportional to the percent decrease in vehicle mass (excluding PEEM mass). For ICE vehicles, a proportionality constant of 0.66 was used (i.e., a $10 \%$ mass reduction corresponds to a $6.6 \%$ reduction in fuel consumption), and for HEVs, a constant of 0.59 was used, based on previous vehicle simulations (Pagerit et al. 2006; Brooker 2011). For PHEVs, it was assumed that the proportionality constant was slightly less than that for HEVs, and 0.55 was used.

The decrease in the amount of fuel consumed per mile that results from reduced friction was attributed to the fuels and lubricant technologies used. A reduction in engine friction of $1 \%$ was assumed to reduce fuel consumption by $0.03 \%$, and a reduction in drivetrain frictional losses of $1 \%$ was assumed to reduce fuel consumption by $0.05 \%$, based on power flows in vehicle simulations (EPA and DOE 2011). A decrease of 10\% in engine and drivetrain friction was assumed for the year 2030, and a 15\% reduction was assumed for 2050 .

Decreases in fuel consumption per mile from reductions in rolling resistance and aerodynamic resistance were estimated but were not attributed to the DOE/EERE VTP, since none of its programs support the reduction of rolling resistance or aerodynamic resistance for LDVs.

For ICE vehicles, the remainder of the fuel savings was attributed to improvements in engine combustion efficiency (advanced combustion engine R\&D). For HEVs and PHEVs, half of the remainder of fuel savings was attributed to improvements in engine combustion efficiency, and the other half was attributed to the battery and electric drive technologies used.

Heavy-truck GPRA advanced technology modeling followed a process flow similar to that just described for LDVs. In the first phase, Autonomie was used to analyze the following heavy-vehicle classes and platforms that are consistent with VTP research areas and goals:

- Class 6 pickup and delivery:

- Advanced conventional gasoline spark ignition (SI),

- Advanced conventional diesel compression ignition (CI),

- Parallel hybrid gasoline-electric SI, and

- Parallel hybrid diesel-electric CI; 
- Class 8 line haul:

- Advanced conventional diesel CI,

- Parallel hybrid diesel-electric CI, and

- Series-parallel hybrid diesel-electric CI.

Since use of Autonomie for modeling the VTP heavy vehicles is new this year (2012), some additional analysis was required. First, in order to attribute fuel savings benefits to each of the VTP areas, it is necessary to determine the contribution of component technologies to the average fuel economy improvements reported by Autonomie. Given input assumptions regarding vehicle characteristics, Autonomie provides average power flows and fuel economy for a specified drive cycle. The HTEB model was calibrated to the Autonomie inputs and outputs and then run individually for sets of component technologies associated with each program area. Second, the HTEB model was used to extend the fuel economy modeling to include Class 7 and 8 single-unit trucks, which have different average loading and operating conditions than do line haul trucks. Third, Autonomie currently does not include a cost model for heavy vehicles. Incremental costs for the simulated platforms were therefore developed based on technology characterizations and cost estimates reported in the 2009 National Academy of Sciences assessment of fuel economy technologies for medium- and heavy-duty trucks (TIAX 2009).

In the second phase of GPRA heavy-truck analysis, the fuel economy improvements and estimated costs resulting from combined Autonomie-HTEB analysis were applied to the TRUCK 4.0 choice model (TA Engineering 2010) to project market penetration of the advanced platforms. TRUCK determines market acceptance by comparing incremental costs and the value of fuel savings to buyer preferences for different payback periods. Since the use of fuel-efficient technology is more cost effective for trucks with above-average annual mileage, the payback algorithm is applied to multiple mileage cohorts rather than assuming the fleet average mileage for all trucks. TRUCK then reports market share as a fraction of total miles driven by trucks of a particular model year in the first year of ownership.

For market penetration analysis, two advanced technology packages were defined to represent future advanced technology improvements on medium- and heavy-duty trucks. The "advanced conventional" package included a range of improvements to conventional trucks. The actual technologies that were included changed from year-to-year, starting with low-cost technologies and including higher-cost technologies in later years. The "hybrid" package included hybrid electric technology for both gasoline and diesel trucks in addition to the conventional package improvements.

For the third and final step of the heavy-truck GPRA benefits analysis, fuel use by heavy trucks under the program case was compared to the baseline No Program consumption. For heavy trucks, the VISION model typically is used to project fuel consumption in the program case. Unfortunately, VISION currently is not configured to analyze all the heavy vehicle platforms modeled for the FY13 GPRA analysis. Therefore, the VISION truck sales, age-specific average annual mileage, cumulative scrappage rates, and various correction factors were applied in a new spreadsheet tool that tracks the stock of heavy vehicles sold in 2010 and later. Fuel use by these trucks is calculated by first assuming the simulated fuel economies and TRUCK market penetrations and then assuming the baseline No Program fuel economy for all trucks. The 
difference between these two calculations provides a projection of energy and carbon emission savings due to the DOE program.

The projected heavy-truck fuel consumption and carbon benefits were allocated to each program area by using results from the Autonomie-calibrated HTEB model. The HTEB model was first used to simulate the fuel economy of the baseline truck in each class in 2015, 2030, and 2045. Autonomie inputs and results for the Target case were then applied to the HTEB to simulate technology packages consistent with each program area (hybrid-electric drive-trains, advanced engine technology, and advanced materials/weight reduction. With regard to the fourth program area (fuels and lubricant technologies), the contribution of each package to reduced fuel consumption (gallons per mile) for the total vehicle platform determines the percentage allocation of benefits to that program element. Allocations for 5-year intervals were estimated by using linear interpolation. 


\section{RESULTS OF MODELING: MARKET PENETRATION AND FLEET FUEL ECONOMY}

Sales share projections of LDVs, by drivetrain technology, were estimated for the years 2010 through 2050 by using the $\mathrm{MA}^{3} \mathrm{~T}$ model on the basis of vehicle attributes developed from Autonomie simulations for the No Program and Target cases. The sales share for each drivetrain technology is shown in Figure 5, and sales shares are listed in Table 8 for these two cases. The difference between the market shares estimated for the two cases is listed in Table 9.

Market penetration estimates from $\mathrm{MA}^{3} \mathrm{~T}$ modeling of LDVs show market shares of HEVs and PHEVs increasing over time. For the Target case, HEVs penetrate early, PHEV penetration follows. Diesel vehicles (conventional and hybrids), BEVs, and FCVs achieve only low sales shares in both the No Program and Target cases and are not shown. The penetration estimates for HEVs and PHEVs are significantly higher for the Target case. The PHEV market share in the Target case is more than twice the market share in the No Program case. Differences in market penetration are due to differences in purchase prices and in operating costs (fuel costs and amortized battery replacement costs for PHEV and BEVs). This result indicates the importance of reducing vehicle purchase prices to enable the widespread adoption of vehicles with new drivetrain technologies. This also indicates that market share estimates are sensitive to assumptions about the factors that drive vehicle costs (including the costs of batteries and power electronics, lightweight materials and manufacturing processes, and more efficient engine and drivetrain technologies) as well as to assumptions about fuel prices. $\mathrm{MA}^{3} \mathrm{~T}$ projections of diesel market shares were low, possibly due to modest fuel economy improvements as modeled by Autonomie. With their higher purchase price, diesel vehicles were not projected to compete against the less-expensive, gasoline-powered LDVs. In reality, however, the fuel economy and prices of light-duty diesel vehicles may make them more competitive than these results indicate.

The fleet average fuel economy increases significantly in the Target case when compared with the No Program case. Figure 6 shows the fleet average unadjusted fuel economy for new cars, light trucks, and the entire new LDV fleet for the Target and No Program cases, respectively. In this plot, fuel economy values were revised to reflect the CAFE standards proposed for 2017-2025 (EPA and DOT 2011). The revision assumed that the fleet average fuel economy would conform to the preferred alternative in the Target case, and that the improvement in fuel consumption per mile in the Target case over that in the No Program case is that estimated as described above. By using these revised fuel economy values for new vehicles

and the stock model in VISION, with an assumed on-road degradation factor of 0.80 , the on-road fleet average fuel economies were calculated for both cases.

Figure 7 shows the on-road fleet average for cars, light trucks, and the entire LDV fleet (revised as described above) for the No Program and Target cases. Fuel savings track with increases in on-road fuel efficiency, so the significantly higher on-road fuel economy averages imply significant fuel savings, as discussed next. 


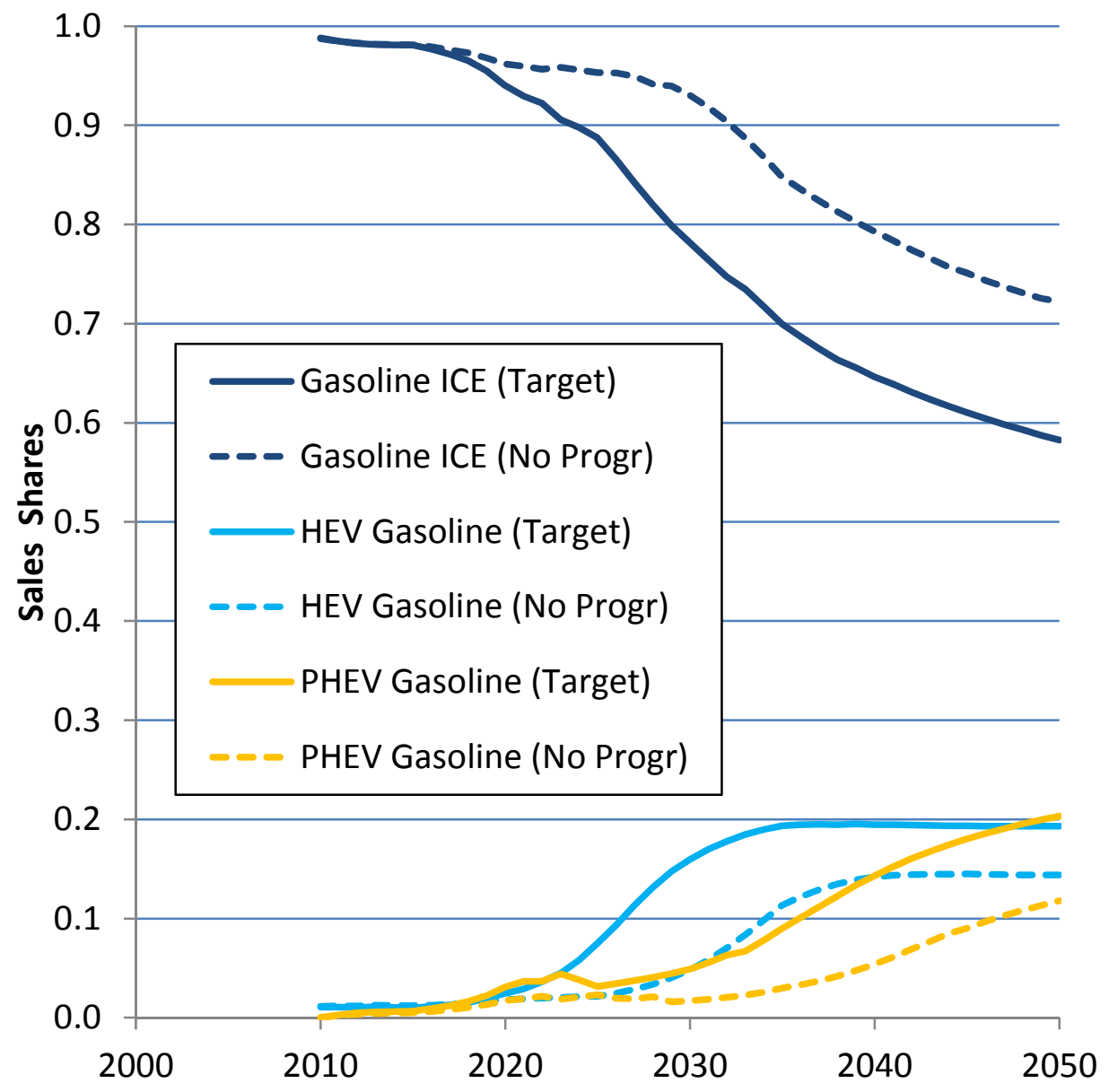

FIGURE 5 LDV Market Penetration Estimates for No Program and Target Cases

Projections of the market penetration of advanced technology heavy trucks are listed in Table 10 as a fraction of total VMT by new trucks in a calendar year. Market penetration estimates are based on the time it takes for the fuel savings to offset the technology's additional cost - a calculation that depends on annual miles of travel. Therefore, fuel-saving technologies are adopted at a higher rate in applications with above-average annual mileage. Since the miles traveled correlate with fuel consumption, using a simple percentage of truck sales does not provide an accurate accounting of new fleet fuel economy.

Both advanced conventional and hybrid technology packages improve the fuel economy of trucks at some added cost. The technologies included in the Adv Conv package vary over time, starting with low-cost technologies and continuing with the gradual addition of more expensive advanced technologies. In all cases, the hybrid platform includes all the improvements found in the advanced conventional package. Although the cost of the advanced conventional trucks increases over time due to the inclusion of additional component technologies, it is assumed that the cost of the hybrid drivetrain gradually decreases due to learning effects and increased production volumes and resulting economies of scale. Since hybridization dominates the cost of these trucks, the cost of the hybrid platform decreases over time. 
TABLE 8 LDV Market Penetration Estimates (\%) for No Program and Target Cases

\begin{tabular}{lrrrrr}
\hline \multicolumn{1}{c}{ Case } & 2010 & 2020 & 2030 & 2040 & 2050 \\
\hline No Program & & & & & \\
Gasoline ICE & 98.7 & 96.2 & 93.0 & 79.3 & 72.2 \\
Diesel ICE & 0.0 & 0.0 & 0.0 & 0.0 & 0.0 \\
HEV gasoline & 1.1 & 1.8 & 4.8 & 14.2 & 14.4 \\
HEV diesel & 0.1 & 0.1 & 0.1 & 0.1 & 0.1 \\
PHEV gasoline & 0.0 & 1.7 & 1.7 & 5.4 & 11.8 \\
BEV & 0.0 & 0.0 & 0.0 & 0.1 & 0.2 \\
FCV & 0.0 & 0.1 & 0.2 & 0.8 & 1.2 \\
Target & & & & & \\
Gasoline ICE & 98.8 & 94.0 & 78.2 & 64.6 & 58.2 \\
Diesel ICE & 0.0 & 0.0 & 0.0 & 0.1 & 0.1 \\
HEV gasoline & 1.0 & 2.4 & 16.0 & 19.5 & 19.3 \\
HEV diesel & 0.1 & 0.2 & 0.1 & 0.1 & 0.1 \\
PHEV gasoline & 0.0 & 3.1 & 4.9 & 14.3 & 20.3 \\
BEV & 0.0 & 0.0 & 0.2 & 0.2 & 0.2 \\
FCV & 0.0 & 0.2 & 0.5 & 1.2 & 1.6 \\
\hline
\end{tabular}

TABLE 9 Difference (\%) in LDV Market Penetration Estimates between Target and No Program Cases (Target Minus No Program) (Percentages shown are changes in sales shares as a fraction of total LDV sales.)

\begin{tabular}{lrrrr}
\hline \multicolumn{1}{c}{ Case } & 2020 & 2030 & 2040 & 2050 \\
\hline Gasoline ICE & -2.2 & -14.9 & -14.7 & -14.0 \\
Diesel ICE & 0.0 & 0.0 & 0.0 & 0.0 \\
HEV gasoline & 0.6 & 1.2 & 5.3 & 4.9 \\
HEV diesel & 0.1 & 0.0 & 0.0 & 0.0 \\
PHEV gasoline & 1.4 & 3.2 & 8.9 & 8.6 \\
BEV & 0.0 & 0.2 & 0.1 & 0.0 \\
FCV & 0.1 & 0.3 & 0.4 & 0.4 \\
\hline
\end{tabular}




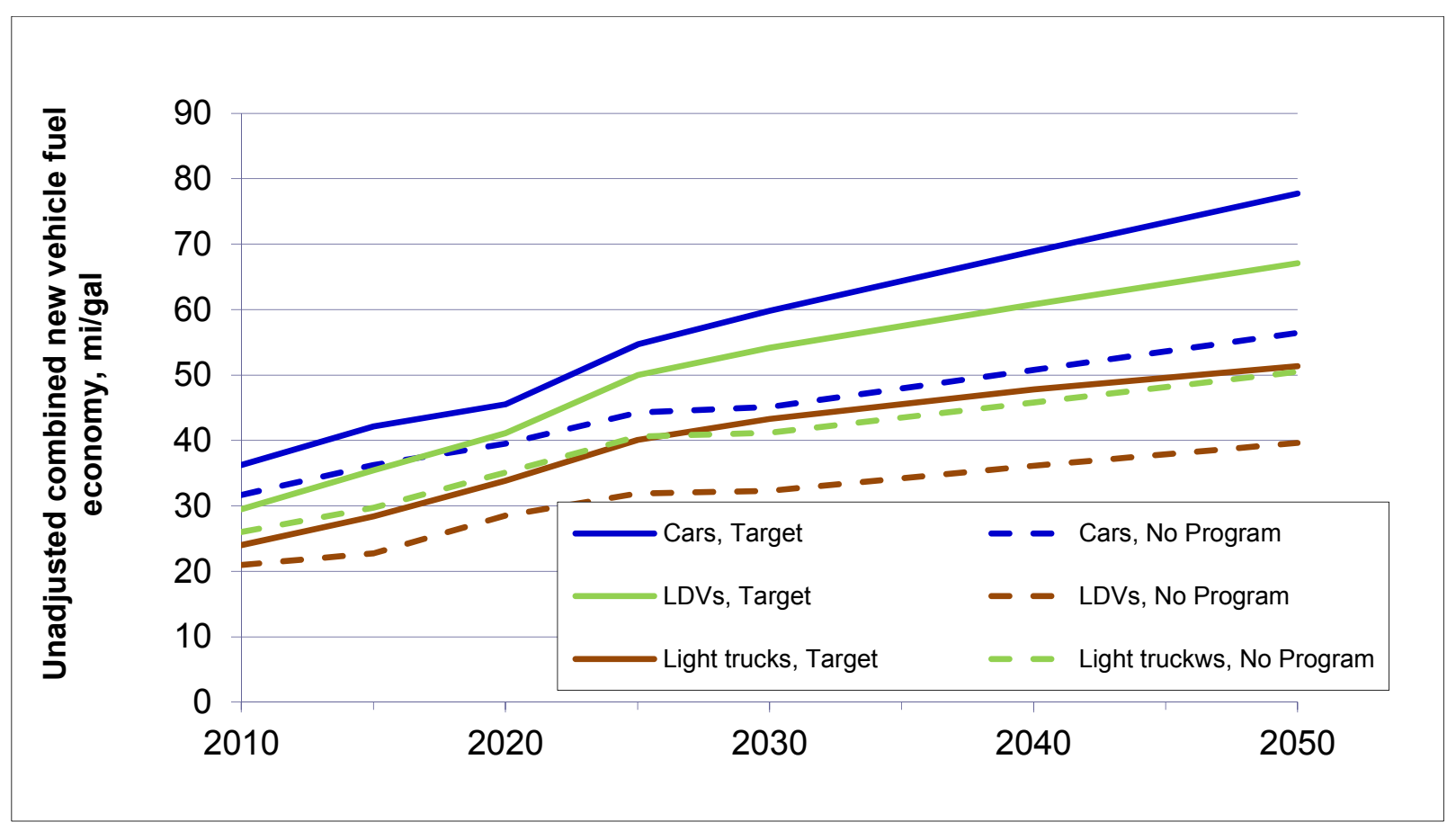

FIGURE 6 Fleet-Average Fuel Economy of New Cars, Light-Duty Trucks, and LDV Fleet for the No Program Case (dashed lines) and Target Case (solid lines) (Values were revised so that the Target case meets proposed CAFE standards.)

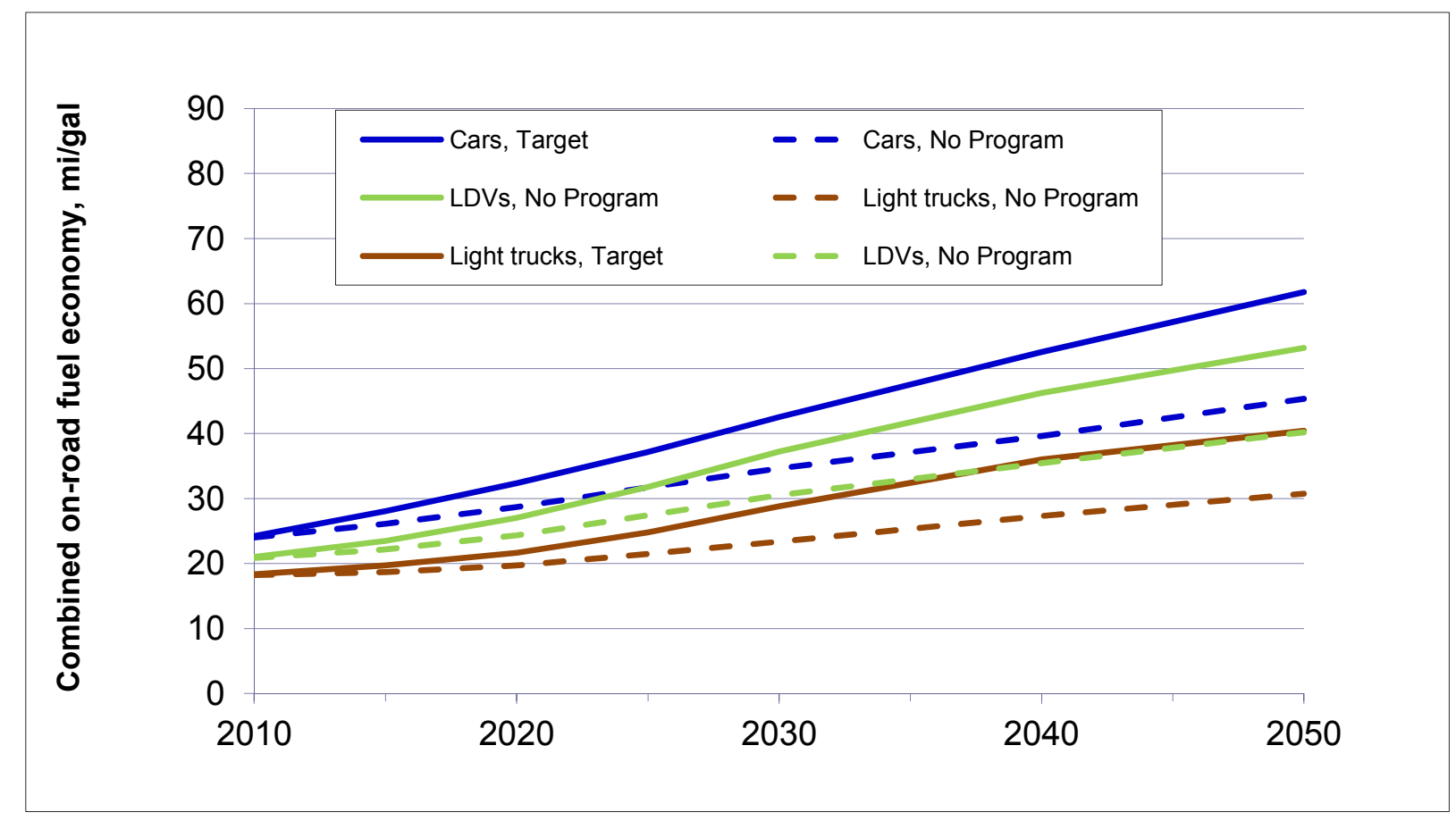

FIGURE 7 Average On-Road Fuel Economy of New Cars, Light-Duty Trucks, and LDV Fleet for the No Program Case (dashed lines) and Target Case (solid lines) (Values were revised so that the Target case meets proposed CAFE standards.) 
TABLE 10 Medium- and Heavy-Duty Truck Market Penetration Estimates for the Target Case, as Percentage (\%) of VMT

\begin{tabular}{lcccc}
\hline \multicolumn{1}{c}{ Vehicle } & & & & \\
& 2020 & 2030 & 2040 & 2050 \\
\hline Medium (Class 3-6) diesel & & & & \\
$\quad$ Baseline & 90.8 & 87.9 & 83.0 & 82.3 \\
Advanced conventional & 5.7 & 5.6 & 8.2 & 8.6 \\
$\quad$ Diesel HEV & 3.5 & 6.5 & 8.7 & 9.1 \\
Medium (Class 3-6) gasoline & & & & \\
Baseline & 83.6 & 82.6 & 82.0 & 81.2 \\
Advanced conventional & 16.3 & 17.0 & 17.5 & 18.3 \\
Gasoline HEV & 0.1 & 0.5 & 0.5 & 0.5 \\
Heavy (Class 7, 8) combination unit & & & & \\
Baseline diesel & 23.9 & 24.0 & 24.4 & 24.0 \\
Advanced conventional diesel & 68.0 & 59.0 & 54.6 & 53.8 \\
Diesel HEV & 8.1 & 17.0 & 21.1 & 22.1 \\
Heavy (Class 7, 8) single unit & & & & \\
Baseline diesel & 83.1 & 84.7 & 85.1 & 84.6 \\
Advanced conventional diesel & 16.2 & 13.8 & 13.0 & 12.6 \\
Diesel HEV & 0.7 & 1.5 & 1.9 & 2.7 \\
\hline
\end{tabular}

For medium-sized trucks, the market share of advanced conventional and hybrid trucks steadily increases over time, since these technologies offer better vehicle performance and since fuel costs rise. However, the hybrid technology platform attains a market share of only $9 \%$ in diesel trucks and of less than $1 \%$ in gasoline trucks, despite offering significant improvements in fuel economy. This low share is due to the low number of miles traveled by these trucks each year, which results in long payback periods.

The trend is somewhat different for heavy Class 7 and 8 trucks, with the advanced conventional platform achieving high market penetration in the early years. Then, the share of this platform gradually decreases over time, as it becomes more expensive and as the hybrid platform begins to penetrate some. This truck class is dominated by long-haul trucks, many of which travel more than 100,000 miles per year. The relatively inexpensive technologies included in the advanced conventional platform offer modest improvements in fuel economy that are cost effective for nearly all of these drivers. In reality, these market shares may not be realized, particularly in the early years, because noneconomic factors may limit these heavy vehicles' attractiveness or because the vehicles may not be available. Overall, the fuel economy of the new heavy vehicle fleet is markedly improved. Figure 8 shows the new fleet-average fuel economy for each truck class (Class 3-6 gasoline, Class 3-6 diesel, Class 7 and 8 single-unit, and Class 7 and 8 combination) for the No Program case and for the Target case. Although some improvement in fuel economy is projected for Class 7 and 8 trucks for the No Program case, significant improvement is projected for the Target case. Class 7 and 8 combination trucks (longhaul tractor trailers) show the most improvement, due to advances in conventional technology 
and to the sizable sales share of hybrid trucks. Given the high number of miles traveled by these vehicles each year, these improvements have the potential to save a significant amount of fuel.

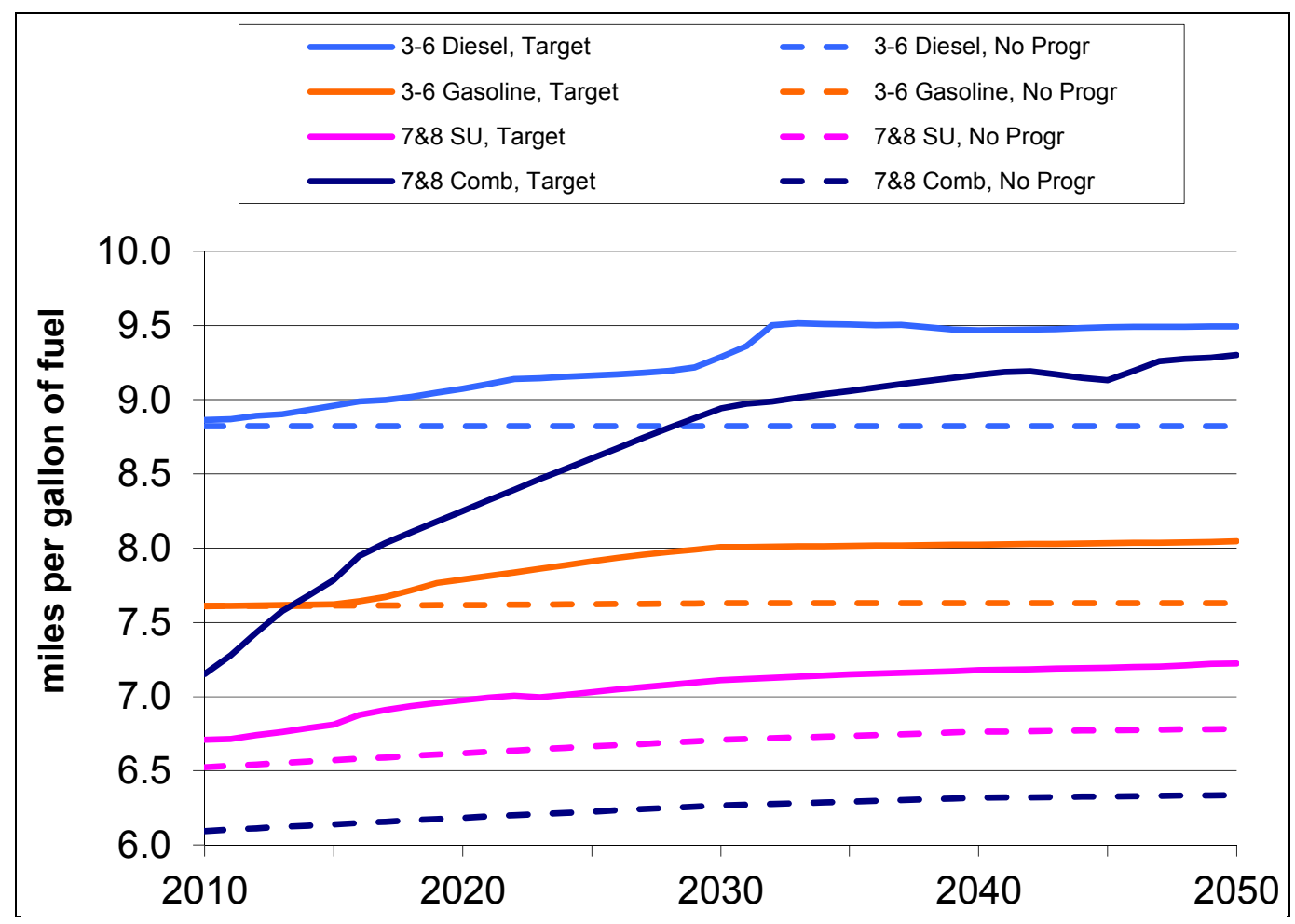

FIGURE 8 Fleet-Average Fuel Economy of Medium- and Heavy-Duty Trucks for the No Program Case (dashed lines) and Target Case (solid lines) 


\section{RESULTS OF MODELING: OVERALL BENEFITS FOR THE VEHICLE TECHNOLOGIES PROGRAM}

Fuel savings, primary energy savings, and GHG reductions for the entire U.S. fleet and the benefits from both LDV and heavy trucks were estimated as described previously. Table 11 shows the total benefits estimated from VTP technologies.

The issue of energy security is largely an issue of oil security. Since the transportation sector accounts for about $70 \%$ of the oil consumed in the United States, reductions in the use of oil for transportation are therefore necessary for the nation to move toward energy security. The estimates of the benefits from the VTP show that a successful program could reduce oil use in 2030 by 1.8 million bpd (barrels or bbl per day). In relative terms, these oil savings amount to just over $10 \%$ of total AEO-projected transportation oil use in 2030.

The estimated cumulative carbon emission benefit in 2030 is 3,700 million metric tons ( $\mathrm{t}$ ) of carbon dioxide $\left(\mathrm{CO}_{2}\right)$; again, these estimates are shown in Table 9. These $\mathrm{CO}_{2}$ reductions are substantial and will help the nation move toward a lower GHG total in 2030. Various dollar values have been placed on a ton of $\mathrm{CO}_{2}$. Assuming $\mathrm{CO}_{2}$ values that go from $\$ 10$ to $\$ 50$ per metric ton, these estimated VTP carbon reductions would range in value from $\$ 40$ billion to more than $\$ 200$ billion.

Reductions in primary energy production can have economic benefits, since the money used to produce this energy can be spent on other goods or economic activity. It is interesting to consider the benefit of improved fuel economy to the consumer as a function of miles-per-gallon (mpg) improvement, oil savings, and consumer savings. The mpg improvement metric in Table 9 serves as a means of personalizing the oil savings metrics: Improved fuel economy reduces the individual consumption of oil for personal mobility and therefore reduces consumer expenditures. However, the increased fuel economy shown in Table $9-26 \%$ in 2030 and $27 \%$ by 2050 - does not capture the full benefit to the consumer. The increase in average U.S. fuel economy means that vehicle drivers use fuel more efficiently, and they thus depend less on large amounts of petroleum fuel, and they are therefore more insulated from potential oil shocks. This decreased dependency on oil increases further as consumers move from conventional ICE vehicles to electric-drive vehicles (PHEVs and EVs), which give drivers the opportunity to use a motive force derived entirely from sources other than petroleum.

Oil security considerations are especially important in light of the presumption in EIA's AEO publication, which serves as the foundation for the baseline cases used herein. This presumption is that the availability of the petroleum supply will be sufficient to meet demand. In a future where that presumption does not hold, oil shocks would be more likely. Shielding America's transportation sector from being vulnerable to such shocks is critical. Conversely, it is possible that if efficiency and renewable energy measures in nontransportation sectors were sufficiently successful on a global scale, petroleum could out-supply demand, which would keep prices low. These low prices would, in turn, inhibit the penetration of advanced technology vehicles and decrease the benefits attributed to the VTP described in this report. 
The significant premium placed on oil security in the United States is worth exploring further than by simply studying what is indicated by the reduced oil use figures just mentioned. According to an analysis by ORNL (Greene et al. 2007, Figure 41, page 42), oil security benefits can be estimated. Oil security net benefits are calculated as a reduction in the damage done to the U.S. economy (as a consequence of the VTP) in future scenarios incorporating oil supply disruptions. The benefits that can be measured monetarily are (1) the transfer of wealth, (2) economic surplus losses, and (3) macroeconomic disruption costs. The transfer of wealth is equal to the quantity of actual oil imports at the higher price, multiplied by the difference between the actual price of oil and what the price would have been in a competitive (or undisrupted) market. Economic surplus losses are deadweight losses that accompany changes in the amounts of oil supplied and in prices. Macroeconomic disruption costs are those that occur when sudden changes in the oil price cause economic dislocations that result in temporary underemployment and misallocation of resources, and thereby a temporary excess loss of gross domestic product (GDP) beyond what the higher price level alone would induce. These disruption costs result from job destruction and creation, and they cause a temporary period of increased unemployment and lost productivity. David Greene and Paul Leiby, who developed the Oil Security Metrics Model, estimated the dollar savings from a 1.6 million bpd oil savings in 2030 from using HEVs. Assuming that their estimates would be similar for the estimated oil savings in 2030 of 1.91 million bpd, the following range of net oil security benefits resulted: $\$ 22$ to $\$ 58$ billion. The low value of $\$ 22$ billion is based on the assumption that the Organization of the Petroleum Exporting Countries (OPEC) maintains its production and that ORNL Method 1 is employed. Method 1 measures security benefits as reductions in the three types of economic costs caused by oil supply disruptions: (1) the transfer of wealth from the U.S. economy to oil exporting economies, (2) producers' and consumers' surplus losses as a result of the higher oil prices, and (3) macroeconomic disruption losses resulting from oil price shocks. The high value of $\$ 58$ billion is based on the assumption that OPEC maintains the price of oil and that ORNL Method 2 is employed. Method 2 follows the National Academy of Science Committee's recommendations to measure economic net benefits during normal, or undisrupted, market conditions but, in future scenarios, to incorporate oil supply disruptions. The difference in macroeconomic disruption costs must be added to the oil cost savings in Method 2 to obtain an estimate of the total economic security benefits. These oil security benefits are very large and have a positive effect on the nation's economy.

Taken together, these benefits demonstrate that a successful VTP will significantly reduce (1) oil consumption (and thus dependence on oil), thereby saving energy; (2) $\mathrm{CO}_{2}$ emissions; and (3) consumer energy expenditures. Moreover, the VTP offers additional benefits that are not explicitly captured in the table, those of maintaining Americans' personal mobility and reducing their exposure to potential oil price shocks. 
TABLE 11 Vehicle Technologies Program Benefits Metrics ${ }^{\mathrm{a}}$

\begin{tabular}{|c|c|c|c|c|c|}
\hline \multirow[b]{2}{*}{ Impact } & \multirow[b]{2}{*}{ Metric } & \multicolumn{4}{|c|}{ Year } \\
\hline & & 2015 & 2020 & 2030 & 2050 \\
\hline \multirow[t]{4}{*}{$\begin{array}{l}\text { Energy } \\
\text { security }\end{array}$} & $\begin{array}{l}\text { Oil savings, cumulative } \\
\text { (billion bbl) }\end{array}$ & 0.8 & 2.5 & 8.3 & 27.0 \\
\hline & $\begin{array}{l}\text { Oil savings, annual } \\
\text { (million bpd) }\end{array}$ & 0.64 & 1.12 & 1.91 & 2.86 \\
\hline & $\begin{array}{l}\text { New vehicle mpg } \\
\text { improvement }(\%)^{\mathrm{b}} \\
\text { LDVs } \\
\text { HTs }\end{array}$ & $\begin{array}{l}19 \\
18\end{array}$ & $\begin{array}{l}17 \\
21\end{array}$ & $\begin{array}{l}32 \\
25\end{array}$ & $\begin{array}{l}33 \\
27\end{array}$ \\
\hline & $\begin{array}{l}\text { On-road mpg } \\
\text { improvement }(\%)^{\mathrm{b}} \\
\text { LDVs } \\
\text { HTs } \\
\end{array}$ & $\begin{array}{l}6 \\
8 \\
\end{array}$ & $\begin{array}{l}11 \\
14 \\
\end{array}$ & $\begin{array}{l}22 \\
21 \\
\end{array}$ & $\begin{array}{l}32 \\
26 \\
\end{array}$ \\
\hline \multirow[t]{2}{*}{ Environmental } & $\begin{array}{l}\mathrm{CO}_{2} \text { emissions reduction, } \\
\text { cumulative (million } \mathrm{CO}_{2} \text { ) }\end{array}$ & 348 & 1,137 & 3,700 & 11,682 \\
\hline & $\begin{array}{l}\mathrm{CO}_{2} \text { emissions reduction, } \\
\text { annual (million } \mathrm{CO}_{2} / \mathrm{yr} \text { ) } \\
\text { LDVs } \\
\text { HTs } \\
\text { Total } \\
\end{array}$ & $\begin{array}{c}80 \\
28 \\
108 \\
\end{array}$ & $\begin{array}{c}137 \\
51 \\
188 \\
\end{array}$ & $\begin{array}{c}224 \\
90 \\
314 \\
\end{array}$ & $\begin{array}{l}289 \\
148 \\
437 \\
\end{array}$ \\
\hline \multirow[t]{2}{*}{ Economic } & $\begin{array}{l}\text { Primary energy savings, } \\
\text { cumulative (quads) }\end{array}$ & 4 & 13 & 44 & 138 \\
\hline & $\begin{array}{l}\text { Primary energy savings, } \\
\text { annual (quads/yr) }\end{array}$ & 1.7 & 3.0 & 5.0 & 6.9 \\
\hline
\end{tabular}

a "Reductions" and "savings" are calculated as the difference between the results from the baseline (No Program) case (i.e., in which there is no future DOE funding for this technology) and the results from the program case (i.e., in which requested DOE funding for this technology is received and is successful). All cumulative metrics are based on results beginning in 2011.

${ }^{\mathrm{b}}$ Improvement relative to baseline (No Program) fleet in the same year. Note: LDV fuel economies shown here were revised to reflect LDV CAFE standards proposed for 2017 through 2025. 


\section{REFERENCES}

Brooker, A., 2011, unpublished results of simulations of vehicle fuel economy with lightweighting, performed at the National Renewable Energy Laboratory, Golden, Colo.

EPA (U.S. Environmental Protection Agency) and DOE (U.S. Department of Energy), 2011, Fuel Economy: Where the Energy Goes, http://www.fueleconomy.gov/feg/atv.shtml, accessed Nov. 11, 2011.

EPA and DOT (U.S. Department of Transportation), 2011, “2017 and Later Model Year LightDuty Vehicle Greenhouse Gas Emissions and Corporate Average Fuel Economy Standards," Notice of Proposed Rulemaking, Federal Register, Vol. 76, No. 231, Dec. 1.

Greene, D.L., et al., 2007, Integrated Analysis of Market Transformation Scenarios with HyTrans, ORNL/TM-2007/094, Oak Ridge National Laboratory, Oak Ridge, Tenn.

Pagerit, S., et al., 2006 "Fuel Economy Sensitivity to Vehicle Mass for Advanced Vehicle Powertrains," Paper 2006-01-0665, Society of Automotive Engineers.

Lin, Z., and D.L. Greene, 2010, “A Plug-in Hybrid Consumer Choice Model with Detailed Market Segmentation," presented at Transportation Research Board 2010 Annual Meeting, http://pubsindex.trb.org/view.aspx?id=910112.

Lin, Z., and D.L. Greene, 2011, "Promoting the Market for Plug-in Hybrid and Battery Electric Vehicles: The Role of Recharge Availability," forthcoming in Transportation Research Record, http://trid.trb.org/view.aspx?id=1093420.

TA Engineering, 2010, TRUCK 4.0 Heavy Truck Market Penetration Model Description, Baltimore, Md., May 10.

TIAX, 2009, Assessment of Fuel Economy Technologies for Medium- and Heavy-Duty Vehicles, Final Report, prepared by TIAX, Lexington, Mass., for the National Academy of Sciences, Nov. 19.

Ward, J., et al., 2008, VISION 2008 User's Guide, ANL-08/34, Argonne National Laboratory, Argonne, Ill., http://www.transportation.anl.gov/pdfs/TA/534.pdf. See also http://www. transportation.anl.gov/modeling_simulation/VISION/index.html. 


\section{Argonne}

\section{Energy Systems Division}

Argonne National Laboratory

9700 South Cass Avenue, Bldg. 362

Argonne, IL 60439-4815

www.anl.gov 